\title{
Folate Polyglutamylation is Required for Rice Seed Development
}

\author{
Nampeung Anukul • Riza Abilgos Ramos • Payam Mehrshahi • \\ Anahi Santoyo Castelazo • Helen Parker • Anne Diévart • Nadège Lanau • \\ Delphine Mieulet • Gregory Tucker • Emmanuel Guiderdoni • David A. Barrett • \\ Malcolm J. Bennett
}

Received: 8 June 2009 / Accepted: 6 May 2010 / Published online: 16 June 2010

(C) Springer Science+Business Media, LLC 2010

\begin{abstract}
In plants, polyglutamylated folate forms account for a significant proportion of the total folate pool. Polyglutamylated folate forms are produced by the enzyme folylpolyglutamate synthetase (FPGS). The FPGS enzyme is encoded by two genes in rice, Os03g02030 and Os $10 g 35940$. Os03g02030 represents the major expressed form in developing seed. To determine the function of this FPGS gene in rice, a T-DNA knockout line was characterised. Disrupting Os03g02030 gene expression resulted in delayed seed filling. LC-MS/MS-based metabolite profiling revealed that the abundance of mono- and polyglutamylated folate forms was significantly decreased in seeds of the knockout line. RT-qPCR detected an increase in the transcript abundance of
\end{abstract}

Electronic supplementary material The online version of this article (doi:10.1007/s12284-010-9040-0) contains supplementary material, which is available to authorized users.

N. Anukul $\cdot$ H. Parker $\cdot$ G. Tucker $\cdot$ M. J. Bennett $(\bowtie)$

School of Biosciences, University of Nottingham,

Nottingham, UK

e-mail: malcolm.bennett@nottingham.ac.uk

\section{R. A. Ramos}

School of Biosciences and School of Pharmacy,

University of Nottingham,

Nottingham, UK

P. Mehrshahi

Department of Biochemistry and Molecular Biology,

Michigan State University,

South Shaw Lane, East Lansing, MI, USA

\section{A. S. Castelazo • D. A. Barrett}

School of Pharmacy, University of Nottingham,

Nottingham, UK

A. Diévart $\cdot$ N. Lanau $\cdot$ D. Mieulet $\cdot$ E. Guiderdoni

CIRAD, UMR DAP,

Montpellier, France folate biosynthesis genes in seed of the knockout plant, whereas the folate deglutamating enzyme $\gamma$-glutamyl hydrolase mRNA level was reduced. Our study has uncovered a novel role for folate polyglutamylation during rice seed development and a potential feedback mechanism to maintain folate abundance.

Keywords Rice $\cdot$ Folate $\cdot$ Folylpolyglutamate synthetase . Glutamylation · Gamma-glutamyl hydrolase

\section{Introduction}

Folate (pteroylglutamate acid) is an essential B vitamin that functions as a cofactor for enzymes in one-carbon metabolism in animal and plant systems. One-carbon units are required for nucleic acid and amino acid biosynthesis plus methylation reactions on lipids, proteins and DNA (Hanson and Gregory 2002).

The folate molecule consists of a pteridine ring, $p$ aminobenzoic acid ( $p \mathrm{ABA})$ and glutamate moieties of between 1 and 11 residues (Fig. 1; Hanson and Gregory 2002). One-carbon units such as formyl (- $\mathrm{CHO})$, methylene $\left(-\mathrm{CH}_{2}-\right)$ and methyl $\left(-\mathrm{CH}_{3}\right)$ can be attached either at the $\mathrm{N} 5$ position of the pteridine ring or at the ${ }_{\mathrm{N} 10}$ position of the $p \mathrm{ABA}$ molecule or bridged between these two positions. Mammals are unable to synthesise folate and thus rely on their diet to meet the daily requirement for this vitamin. Plants are folate auxotrophs and are a major contributor to the human folate requirement. Tetrahydrofolate is synthesised in the mitochondria, as a result of a tricompartmentalised biosynthetic pathway (Fig. 2). The cytosolic compartment is responsible for hydroxymethyldihydropterin (pteridine) synthesis. In chloroplasts, $p \mathrm{ABA}$ is synthesised and then coupled together with cytosolic 
Fig. 1 Chemical structures of tetrahydrofolate and its $\mathrm{C} 1$ substituted derivatives.

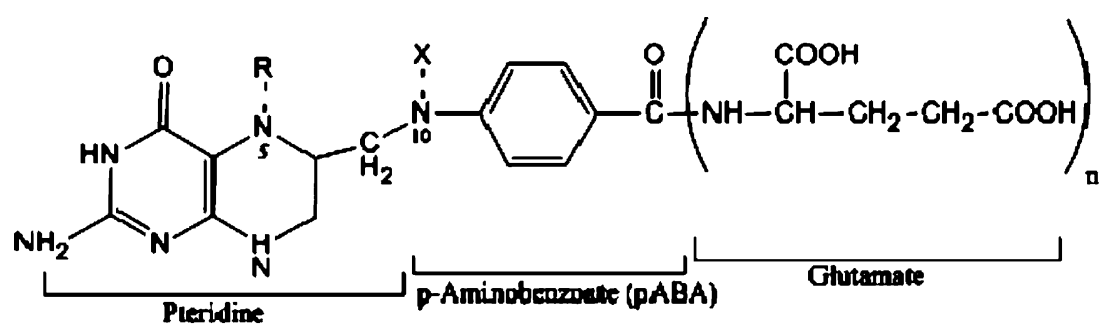

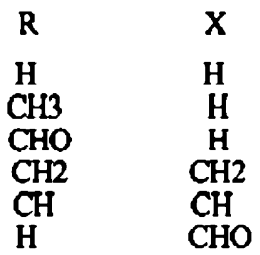

hydroxymethyldihydropterin in the mitochondria to form dihydropterate $\left(\mathrm{H}_{2}\right.$ Pteroate). A glutamate residue is attached to dihydropterate to form dihydrofolate and tetrahydrofolate by dihydrofolate synthetase and dihydrofolate reductase, respectively.

Folate molecules exist in vivo mainly as polyglutamates which are the preferred form by most folate-dependent enzymes (Shane, 1989). Indeed, polyglutamylated 5methyltetrahydrofolate is required for the largest plant $\mathrm{C} 1$ anabolic flux, which converts homocysteine to methionine (Hanson and Roje, 2001; Ravanel et al. 2004). In addition, the glycine-serine interconversion, which links the metabolism of one-, two- and three-carbon compounds, is another sink for the polyglutamylated folates (Bauwe and Kolukisaoglu, 2003, Besson et al. 1993). These glutamate-extended folate molecules are produced by folylpolyglutamate synthetase (FPGS, EC 6.3.2.17). This enzyme is responsible for sequentially conjugating L-glutamic acid residues with monoglutamate folate via $\gamma$-carboxyl peptide linkages (Suh et al., 2001). Studies of folate polyglutamylation in yeast and mammalian systems have shown that this post-biosynthetic processing protects this molecule from oxidative breakdown by protein binding (Suh et al. 2001, Jones and Nixon 2002), which is favoured by polyglutamylation resulting in folate stability. Furthermore, protein binding aids the protection of deglutamylation of polyglutamyl folates $\gamma$-glutamyl hydrolase (GGH; Wang et al. 1993). Hence, these mechanisms could retain cellular polyglutamylated folate forms for the demand of cells. In plants, the degree of glutamylation varies between organs (Lowe et al. 1993). Tetra- and pentaglutamylated folate forms are reported predominant in pea leaves (Imeson et al. 1990); whereas diglutamylated folate is predominant in carrot root (Cossins and Chen 1997).

In Arabidopsis, three FPGS genes are reported to encode distinct mitochondrial, cytoplasmic and plastidial isoforms of this enzyme. The tri-compartmentation of FPGS in Arabidopsis was reported as being a key to the homeostasis of folate and folate-dependent metabolites (Ravanel et al. 2001). It is therefore surprising that rice contains only two FPGS isoforms in rice, namely, FPGS Os03g02030 and FPGS Os $10 \mathrm{~g} 35940$. The presence of only two FPGS isoforms in rice may be indicative of either dual targeting of one or both proteins to multiple compartments and/or the movement of folate polyglutamates between the source and sink sites.

In this paper, we investigated the developmental function of FPGS Os03g02030. Characterisation of a rice knockout mutant revealed a role for this FPGS isoform during seed filling, for maintaining mono- and polyglutamylated folate levels and revealing that the transcript abundance of folate biosynthesis genes was subject to feedback regulation.

\section{Results}

FPGS genes are differentially expressed in rice tissues

FPGS gene sequences were identified in the rice genome based on their homology to the Arabidopsis FPGS genes, At5g05980, At3g55630 and At3g10160. Arabidopsis protein sequences were used to identify their orthologues in rice using the Gramene database (http://www.gramene.org/) employing the BLASTP tool. The rice genome contains two genes, Os03g02030 and Os10g35940, which encode two putative FPGS proteins. They present $50-57 \%$ protein identity with three Arabidopsis FPGS isoforms (The homology of Arabidopsis and rice protein sequences is provided in the Electronic Supplementary Material Fig. S1). The FPGS enzyme requires three substrates, ATP, tetrahydrofolate and glutamate molecules, which bind different sites on the FPGS molecule. The putative rice FPGS protein sequences contain all the previously reported functional motifs (Sun et al., 2001; Fig. S1). Although three Arabidopsis FPGS genes encode compartment-specific 


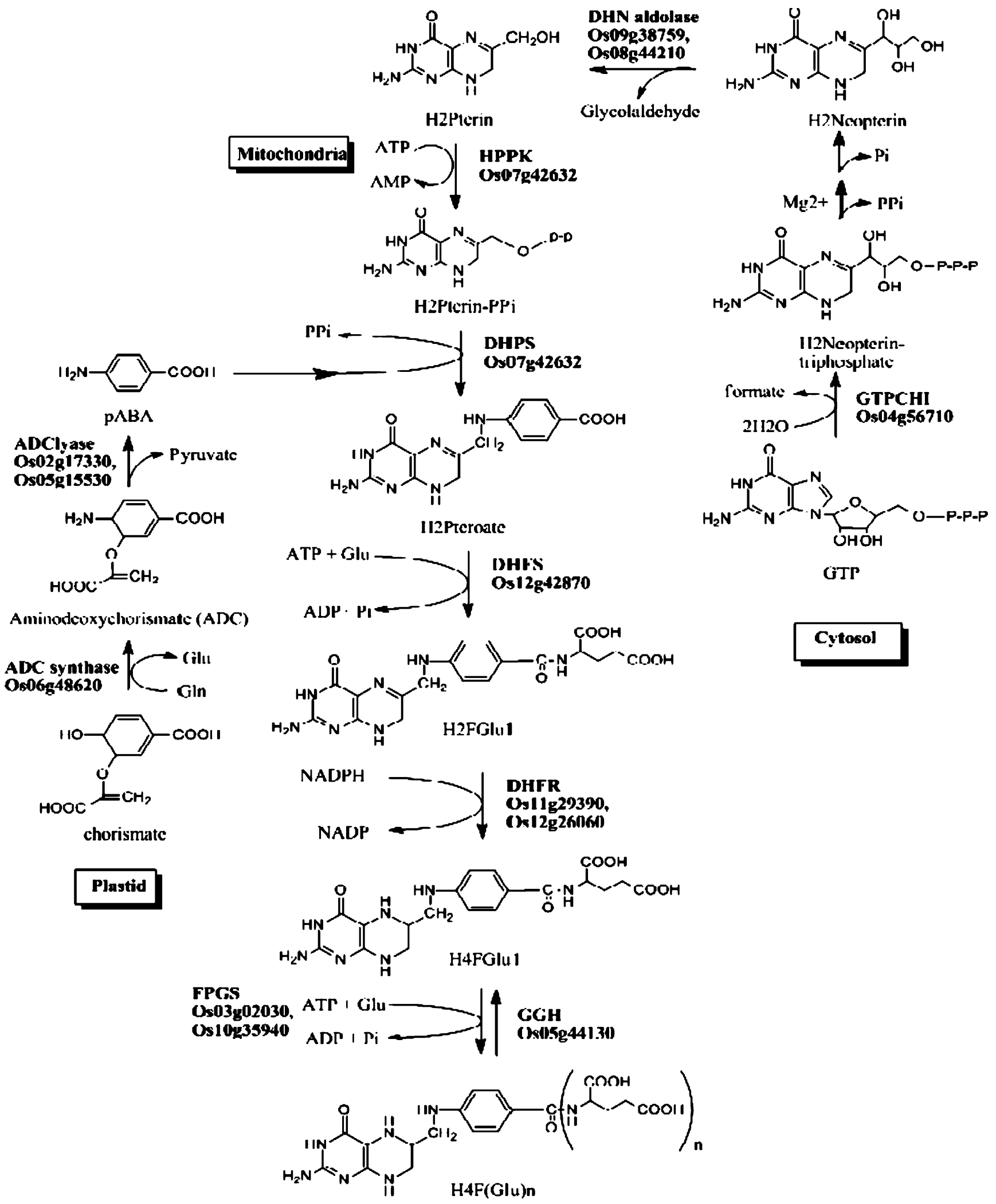

Fig. 2 Folate biosynthesis pathway in plant. Enzymes responsible in metabolism are shown in bold; GTP cyclohydrolase I (GTPCHI), dihydroneopterin aldolase (DHN aldolase), aminodeoxychorismate synthase (ADC synthase), aminodeoxychorismate lyase (ADC lyase), hydroxymethyldihydropterin pyrophosphate kinase (HPPK), dihy- dropteroate synthase (DHPS), dihydrofolate synthase (DHFS), dihydrofolate reductase $(D H F R)$ and folypolyglutamate synthase (FPGS) and gamma-glutamyl hydrolase $(G G H)$. The Gramene gene codes (obtained from www.gramene.org) encoding these enzymes in rice are presented in bold along with the enzyme names. 
isoforms, no experimental study reports localisation of rice FPGS isoforms. However, based on the signal sequence prediction software such as TargetP, both mitochondrial and plastidial signal peptides have been suggested in the expanded N-terminal of both rice FPGS isoforms (data not shown).

Reverse transcriptase-quantitative polymerase chain reaction (RT-qPCR) assays were performed initially on cDNA isolated from coleoptiles, radicles, mature leaves, mature roots, flowers and dry mature grains of Nipponbare using gene-specific primers designed against both rice FPGS sequences (Fig. 3). Interestingly, FPGS transcript abundance in leaf and grain were significantly different. The mRNA level of FPGS Os $10 \mathrm{~g} 35940$ was more abundant than FPGS Os03g02030 in leaf tissue, whilst FPGS Os03g02030 transcripts were higher in all other tissues including grains. Their patterns of expression suggest that during rice development, FPGS Os $10 g 35940$ is the major isoform in leaves, whilst FPGS Os03g02030 was expressed predominantly in grains.

\section{Identification of a FPGS Os03g02030 knockout line}

To investigate whether the Os03g02030 FPGS gene functions during seed development, a T-DNA insertion line was characterised. Information about T-DNA insertion lines were obtained from the OryGenes website (http://orygen esdb.cirad.fr). Seed for insertion line FST number A16772 which disrupts the FPGS Os03g02030 gene in rice Oryza sativa cv. Dongjin background was obtained from Postech (http://www.postech.ac.kr/life/pfg/risd). The FPGS Os03g02030 gene contains 16 exons, with the T-DNA inserted within the second exon (Electronic Supplementary Material Fig. S2).

Genotyping of the T-DNA insertion mutant was performed by Southern and PCR analysis. Southern analysis was performed on FST number A16772 plants using a TDNA specific hygromycin probe and a FPGS gene-specific probe (Fig. S3). The hygromycin and gene specific probe revealed that plant numbers 5 and 15 were homozygous with a single T-DNA insertion. The progeny of plant number 5 was chosen for further analysis. To confirm the original southern blot result, PCR was performed using FPGS gene-specific primers and T-DNA primers (Fig. 4). PCR results indicated that plant number 5 contained a homozygous T-DNA insertion within the FPGS Os03g02030 gene (Fig. 5a).

RT-qPCR was also performed to monitor the impact of the T-DNA insertion on FPGS Os03g02030 mRNA abundance using cDNA specific primers, 3gE1_for and $3 \mathrm{gE} 1$ 1_rev (Fig. 4). FPGS Os03g02030 mRNA was not detected in the T-DNA line whereas transcripts were detected for the actin positive control (Fig. 5b). Hence, line number 5 represented a loss of function allele for FPGS Os03g02030. This $F P G S$ knockout line is referred as fpgs $03 \mathrm{~g}$ in the rest of the text.

The fpgs $03 \mathrm{~g}$ mutant exhibits delayed seed filling

The phenotype of the fpgs $03 \mathrm{~g}$ mutant line was characterised throughout the rice life cycle. Twenty fpgs $03 \mathrm{~g}$ mutant plants were grown in soil in controlled conditions and their phenotypes were monitored at every stage of development. From the seedling stage until the stem elongation stage, the

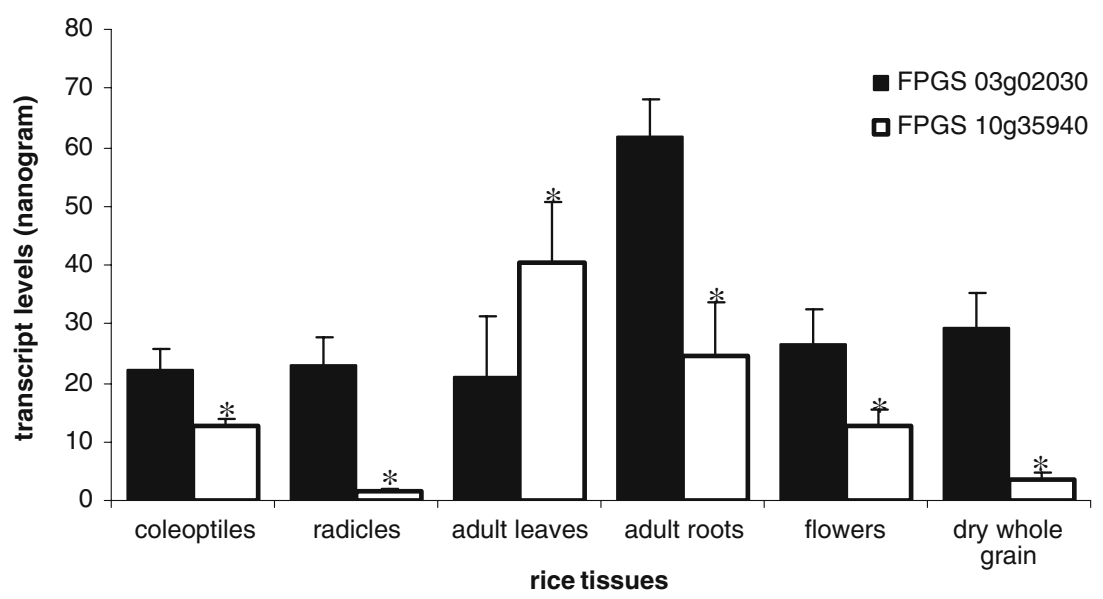

Fig. 3 Expression profiles of FPGS genes Os03g02030 and Os $\log 35940$ in different rice tissues of Nipponbare wild type using RT-qPCR. The transcript abundance is provided in nanograms representing the amount of mRNA expressed from a particular gene. The transcript abundance for each gene was normalised by the actin transcript which was expressed at an equal amount in all tissues. The transcript abundance of FPGS Os03g02030 and FPGS Os10g35940 are shown in black and white vertical bars, respectively. Each bar represents the mean of triplicate determination and the vertical line indicates the standard deviation. Asterisks represent the significant difference $(P<0.05)$ of transcript abundance of FPGS Os $10 \mathrm{~g} 35940$ compared to that of FPGS Os03g02030 in all samples. 


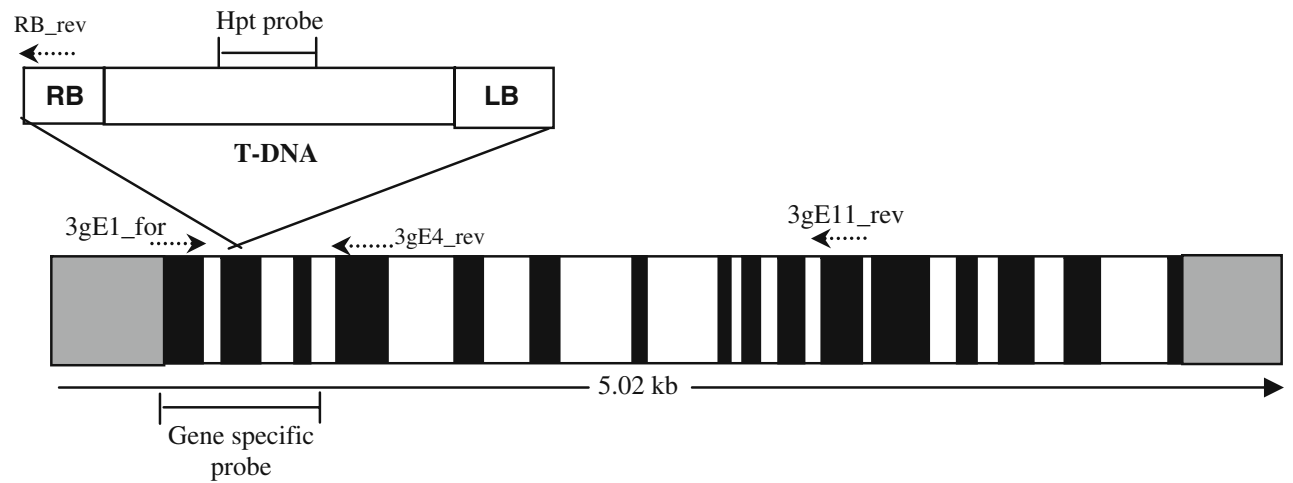

Fig. 4 Map of the T-DNA from the pGA2715 vector and the insert position in exon 2 of the FPGS Os03g02030 gene. $R B$ and $L B$ represent the right and left borders of the T-DNA. Black and white bars represent the exons and introns in the Os03g02030 gene. The

leaves and shoot phenotypes of the knockout mutant appeared wild type (Fig. 6a). However, during seed development, the fpgs03g mutant exhibited slower grain filling and later ripening (Fig. 7b). Observations made every day noted that the knockout rice line was 1 week late in reaching the heading stage compared to wild type and was delayed every subsequent step, reaching the mature stage approximately 2 weeks later than Dongjin wild type (Table 1). Despite the seed development phenotype of the knockout plants, the mature seeds were wild type-like in appearance and ability to germinate (Fig. 6a, d). The germination rate of the fpgs $03 \mathrm{~g}$ mutant was about $95 \%$

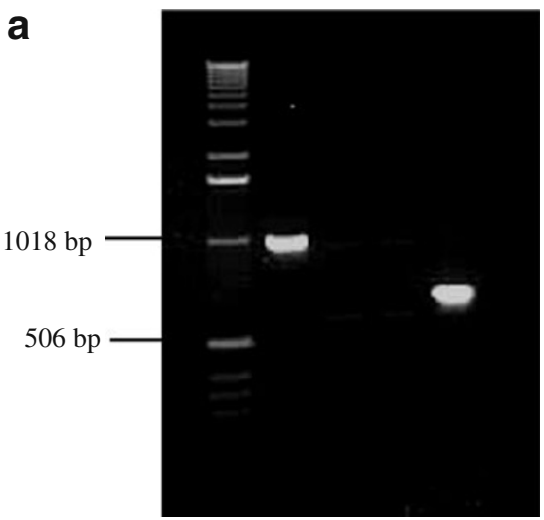

M $1112 \quad 3 \quad 4$

Fig. 5 PCR and RT-PCR analysis of FPGS Os03g02030 T-DNA insertion line 5. DNA and RNA extracted from the third leaves (2week-old) of Dongjin wild type and FPGS Os03g02030 homozygous knockout line number 5 were analysed by PCR (a) and RT-PCR (b). a Lane 1 and 2 were the result from using $3 \mathrm{gE} 1$ for and $3 \mathrm{gE} 4$ rev primers, and the product size of $991 \mathrm{bp}$ was expected. The positive band on this primer pair confirmed the wild-type genotype. Lane 3 and 4 were the result of using $3 \mathrm{gE} 1$ for and RB rev primers, and the expected product size was $667 \mathrm{bp}$. The positive band from this primer pair suggested the presence of the T-DNA insertion. Dongjin wildtype DNA was applied in the PCR reaction of lane 1 and 3, and FPGS dashes show the position of hygromycin (Hpt) and gene-specific probes used in the southern analysis. 3gE1_for, 3gE4_rev, 3gE11_rev and $\mathrm{RB}$ rev are PCR primers.

compared to Dongjin wild type. The number of seeds per ear (approximately 60 seeds) and ears per plant of the fpgs $03 \mathrm{~g}$ mutant were also similar to wild type. Hence, the developmental delay exhibited by the fpgs $03 \mathrm{~g}$ mutant during the seed-setting stage suggested that the FPGS Os03g02030 gene played a key role during the seed filling stage.

Polyglutamylated folate levels were decreased in the fpgs03g mutant seed

To directly determine whether knocking out FPGS Os03g02030 gene function affected the abundance of

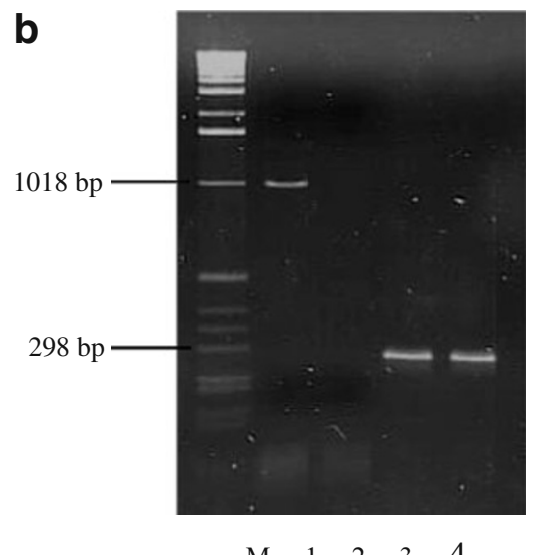

Os03g02030 homozygous knockout line DNA was applied in the PCR reaction of lane 2 and 4 . b Lane 1 and 2 were the RT-PCR result from $3 \mathrm{gE} 1$ for and 3gE1 1_rev primers, and the expected product size was $1,016 \mathrm{bp}$. This primer pair was used to confirm the mRNA expression of FPGS Os03g02030 gene. Lane 3 and 4 were the RT-PCR result from the rice actin primers which the expected band size was $276 \mathrm{bp}$. Actin bands demonstrated an equal amount of loaded RNA. Dongjin wild-type DNA was applied in the RT-PCR reaction of lane 1 and 3, and FPGS Os03g02030 homozygous knockout line DNA was applied in the RT-PCR reaction of lane 2 and 4 . $M$ represents $1-\mathrm{kb}$ ladder standard. 
Fig. 6 The plant phenotypes of fpgs03g and Dongjin wild type a 2-month-old plants, b

2-month-old seeds, c hulled mature dry seeds and $\mathbf{d}$ 4-day-old germinated seeds.
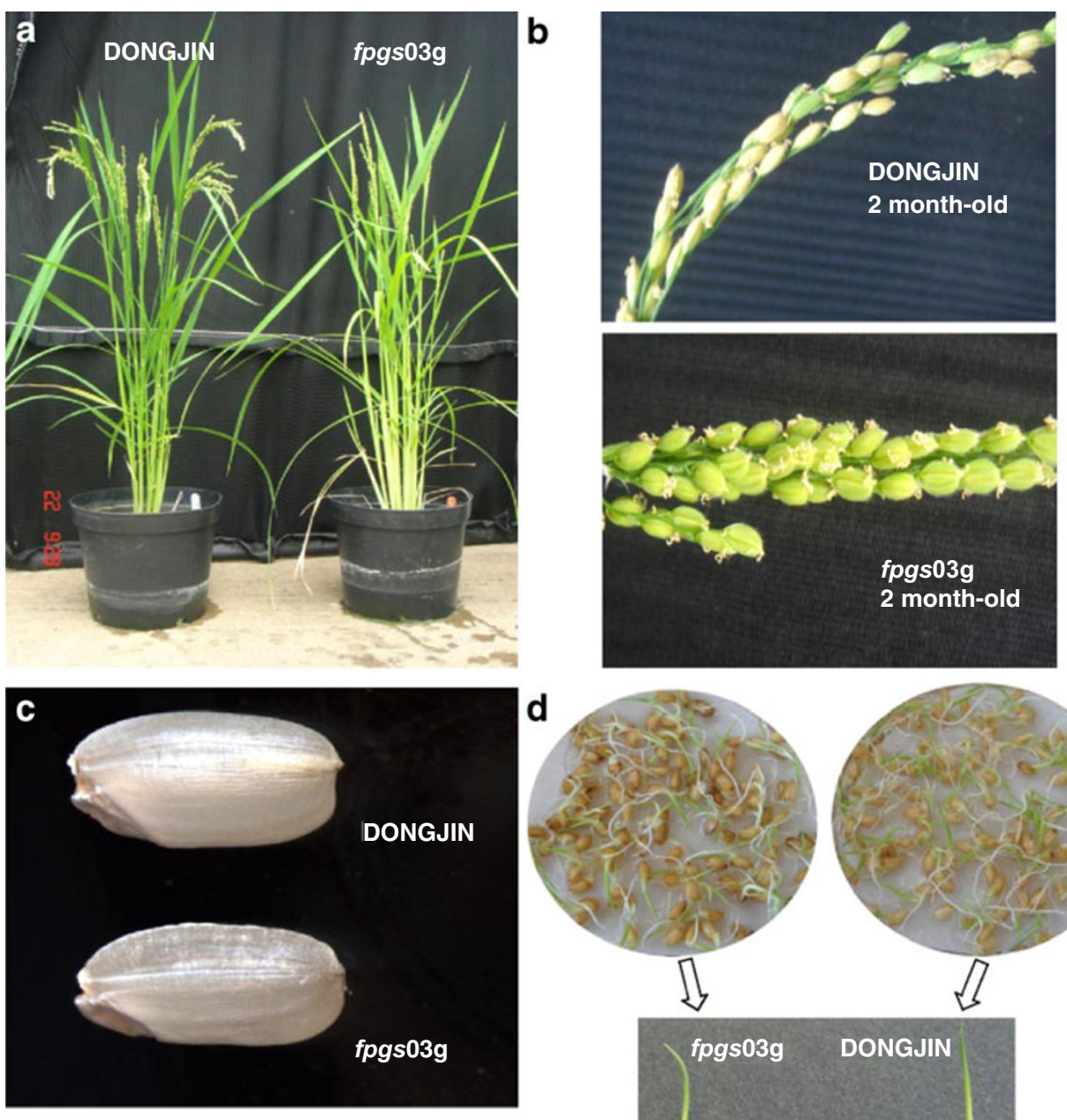

polyglutamylated folates and total folate levels, folate quantification was performed using liquid chromatography/negative ion electrospray ionisation tandem mass spectrometry (LC-MS/MS). The concentration of folate derivatives in rice tissues is summarised in Table 2. The predominant form of monoglutamylated folate detected in rice seeds (S) and leaf (L) was 5-methyltetrahydrofolate. With respect to polyglutamylated folates, only tetra- and pentaglutamylated forms were detected in leaf and seed samples.

The level of the major polyglutamylated folate form 5$\mathrm{CHO}-\mathrm{H}_{4} \mathrm{PteGlu}_{5}$ in $\mathrm{fpgs} 03 \mathrm{~g}$ leaf and seed tissues was significantly lower than the wild type (Table 2). Similarly, $5-\mathrm{CH}_{3}-\mathrm{H}_{4} \mathrm{PteGlu}_{5}$ levels were decreased in only seed tissue (Table 2). In addition, the monoglutamylated folate $5-\mathrm{CH}_{3}-\mathrm{H}_{4}$ PteGlu was significantly reduced only in the seed of the knockout line. Overall, there was a 33\% and $28 \%$ decrease in total folate levels in seed and leaf samples of the knockout line compared to the wild type, respectively. Hence, loss of FPGS 03g02030 gene expression resulted in reduction of both mono- and polyglutamylated folate content.

Transcript abundance of folate biosynthesis genes is up-regulated in the $f p g s 03 \mathrm{~g}$ mutant

To examine the effect of disrupting the Os03g02030 FPGS gene on other folate-related genes, RT-qPCR was performed on cDNA prepared from mRNA isolated from grains of $f p g s 03 \mathrm{~g}$ and Dongjin wild type. Thirteen genes encoding the enzymes in the folate biosynthesis pathway (Fig. 2) were identified in the Gramene database (The list of 

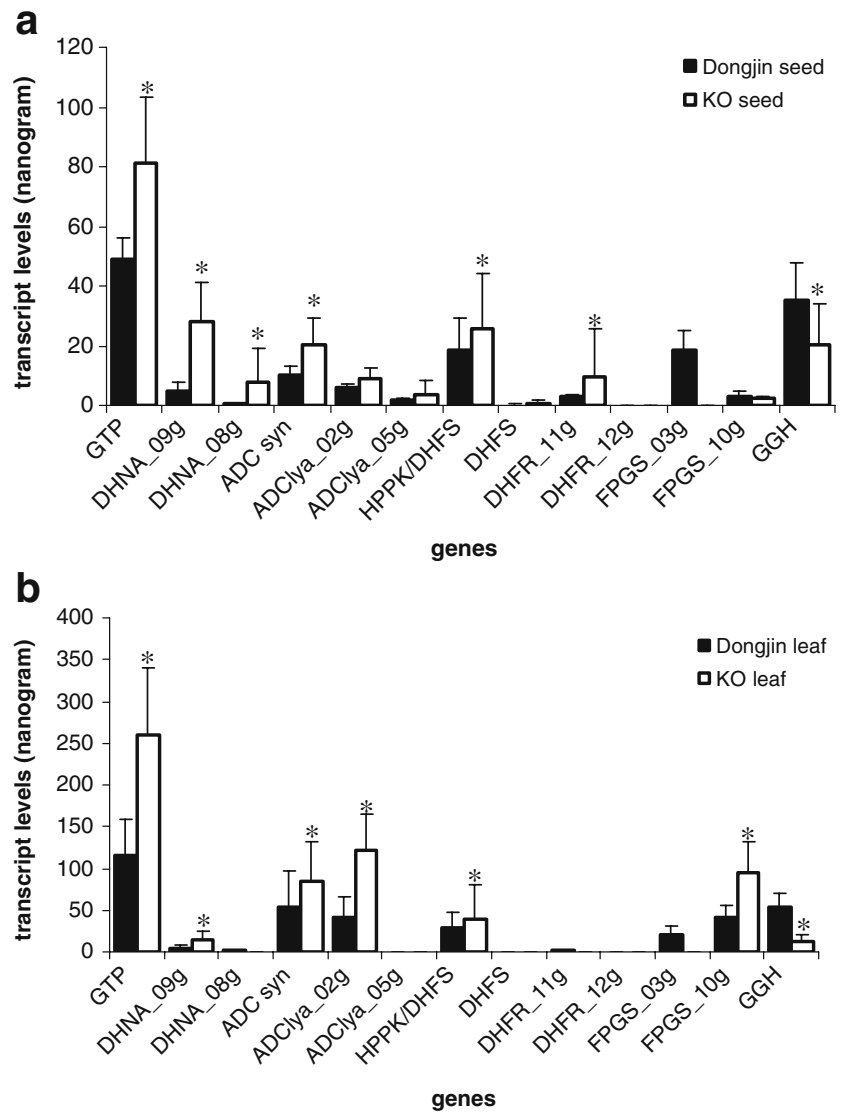

Fig. 7 Expression profiles of folate-related genes in dry mature seeds (a) and leaves (b) of Dongjin and fpgs03g mutant using RT-qPCR. For seed samples, 40 dry mature seeds from ten different plants were pooled per analysis. For leaf samples, the third green leaf from five plants was pooled per analysis. The transcript values are provided in nanograms representing the amount of mRNA for a particular gene relative to the actin transcript. All folate-related genes including GTPCHI LOC Os04g56710 (GTP), DHNA LOC Os09g38759 (DHNA_09g), DHNA LOC_Os08g44210 (DHNA_08g), ADC synthase LOC Os06g48620 (ADC syn), ADC lyase LOC Os02g17330 (ADClya_02 $\mathrm{g}$ ), ADC lyase LOC_Os05g15530 (ADClya_05g), HPPK/ DHPS LOC_Os07g42632 (HPPK/DHPS), DHFS LOC_Os12g42870 (DHFS), DHFR LOC Os11g29390 (DHFR 11g), DHFR LOC Os12g26060 (DHFR 12 $g$ ), FPGS LOC Os03g02030 (FPGS 03g), FPGS LOC_Os10g35940 (FPGS_10g) and GGH LOC_Os05g44130 $(G G H)$ are showed in vertical bars. Each bar represents the mean of triplicate determination and the vertical line indicates the standard deviation. Asterisks represent the significant difference $(P<0.05)$ of transcript abundance compared between knockout and Dongjin wild type within tissues.

all enzymes and genes is provided in the Electronic Supplementary Material Table S1). RT-qPCR probes were designed for all 13 folate-related genes.

In grains (Fig. 7a), the mRNA abundance of almost every biosynthetic gene (GTPCHI, ADC synthase, ADC lyase, $H P P K / D H P S$ ) increased in the fpgs03g knockout line compared to the wild type. The transcripts of most genes increased in the knockout except the FPGS Os10g35940 gene which was expressed at a similar level to the wild type
Table 1 Observation of Developmental Stage of Dongjin and fpgs03g Plants

\begin{tabular}{lll}
\hline Rice developmental stages & \multicolumn{2}{l}{ Days after starting germination } \\
\cline { 2 - 3 } & Dongjin & fpgs03g \\
\hline Germination & 7 & 7 \\
Seedling (third-leaf protuding) & 23 & 23 \\
Tilering and elongation & 40 & 50 \\
Heading & 50 & 59 \\
Flowering & 54 & 64 \\
Milk grain & 61 & 70 \\
Dough grain & 64 & 76 \\
Mature grain & 74 & 87 \\
\hline
\end{tabular}

and $G G H$ which decreased approximately twofold. In leaf (Fig. 7b), the transcript abundance of all genes also increased in the knockout similar to grain except the $F P G S$ Os $10 \mathrm{~g} 35940$ gene which increased approximately twofold.

The transcript abundance of genes encoding selected folate biosynthesis and degradation enzymes (GTPCHI, $A D C$ synthase, HPPK/DHPS, FPGS Os10g35940 and $G G H)$ were also profiled at several stages in developing seed of wild type and fpgs03g (Fig. 8). RT-qPCR revealed that mRNAs of all three monoglutamate folate biosynthesis genes (Fig. 8a, b and c) were elevated at the anthesis stage in the fpgs03g line. This result indicates that the highest requirement of folate in rice seed development is at the flowering stage, and these genes are influenced by lacking FPGS Os03g02030. In contrast, the transcript abundance of FPGS Os10g35940 gene in the FPGS03g line was not increased (Fig. 8d). However, mRNA abundance of the folate-degrading enzyme, GGH, was reduced up to tenfold during seed development (Fig. 8e). GGH is an enzyme which cleaves glutamate residues of the folate molecule as part of the folate degradation and turnover pathway (Orsomando et al. 2005). Hence, our RT-qPCR results suggested the existence of a feedback regulatory system that controls folate abundance in rice seed.

\section{Discussion}

A significant proportion of plant folates exists in a polyglutamylated form (Storozhenko et al. 2007, Orsomando et al. 2005, Díaz de la Garza et al. 2004). This study has employed LC-MS/MS to reveal that approximately $40 \%$ of rice folate forms detected in leaf and $20 \%$ of folate in seed exists either as tetra or penta forms of the $5-\mathrm{CH}_{3}-$ and 5/ $10-\mathrm{CHO}-\mathrm{H}_{4}$ Pte (Table 2). The polyglutamate chain length of folates can be affected by a number of factors of which include the polyglutamylating enzyme FPGS (Chen et al. 1996) and the deglutamylating enzyme GGH (Galivan et al. 
Table 2 Total Folate Levels and Folate Derivatives in Leaf and Seed from Dongjin Wild Type and fpgs03g Mutant

\begin{tabular}{|c|c|c|c|c|c|c|}
\hline \multirow{2}{*}{$\begin{array}{l}\text { Rice Variety } \\
(n=3)\end{array}$} & \multicolumn{6}{|c|}{ Folate Form $(\mu \mathrm{g} / 100 \mathrm{~g})$} \\
\hline & 5- $\mathrm{CH}_{3}-\mathrm{H}_{4} \mathrm{PteGlu}$ & $5-$ and $10-\mathrm{CHO}-\mathrm{H}_{4}$ PteGlu & $5-\mathrm{CH}_{3}-\mathrm{H}_{4} \mathrm{PteGlu}_{4}$ & 5- $\mathrm{CH}_{3}-\mathrm{H}_{4} \mathrm{PteGlu}_{5}$ & 5- $\mathrm{CHO}-\mathrm{H}_{4} \mathrm{PteGlu}_{5}$ & Total Folate \\
\hline Dongjin (L) & $5.16+0.72$ & $1.62+0.24$ & $0.33+0.01$ & $0.7+0.40$ & $4.36+0.47 *$ & $12.17 \pm 0.40^{*}$ \\
\hline fpgs03g (L) & $3.88+0.14$ & $0.79+0.18$ & $0.67+0.01$ & $0.7+0.01$ & $2.65+0.1 *$ & $8.69 \pm 0.10^{*}$ \\
\hline Dongjin (S) & $3.21+0.70^{*}$ & $1.87+0.28$ & $0.33+0.01 *$ & $0.3+0.004^{*}$ & $0.74+0.01 *$ & $6.45 \pm 1.00^{*}$ \\
\hline fpgs03g (S) & $2.13+0.30 *$ & $1.72+0.61$ & $0.11+0.001 *$ & $0.1+0.00 *$ & $0.22+0.01 *$ & $4.28 \pm 0.20 *$ \\
\hline
\end{tabular}

The mean $\pm \mathrm{SD}$ of the folate contents was presented with $n=3$

5- $\mathrm{CH}_{3}-\mathrm{H}_{4}$ PteGlu 5-methyltetrahydropteroylmonoglutamated, 5- $\mathrm{CHO}-\mathrm{H}_{4} \mathrm{PteGlu}$ 5-formyltetrahydropteroylmonoglutamated, 5- $\mathrm{CH}_{3}-\mathrm{H}_{4} \mathrm{Pte} \mathrm{Glu}_{4}$ 5-methyltetrahydropteroyltetraglutamate, $5-\mathrm{CH}_{3}-\mathrm{H}_{4} \mathrm{PteGlu}_{5}$ 5-methyltetrahydropteroylpentaglutamate, 5- $\mathrm{CHO}-\mathrm{H}_{4} \mathrm{PteGlu}$ 5-formyltetrahydropteroylpentaglutamate, $L$ leaf sample, $S$ mature seed sample

${ }^{*} P<0.05$, samples within tissues which are significantly different

2000). Two putative FPGS genes exist in rice. Expression profiling has revealed that the FPGS Os10g35940 transcript level is more abundant in rice leaves, whereas the FPGS Os03g02030 transcript is found at higher levels in most other organs including in rice seed. This study has explored the physiological importance of the FPGS Os03g02030 gene employing a functional genomics approach.

\section{Polyglutamylation of folate affects rice grain filling}

Characterisation of a rice knockout mutant in Os03g02030 revealed that plants lacking this gene product exhibit a delayed seed development phenotype. Seed development was impaired from the heading stage, leading to slower grain filling and late maturation of grains. Folate profiling of fpgs $03 \mathrm{~g}$ knockout revealed the decrease of polyglutamylated folate forms in grain $(0.43 \mu \mathrm{g} / 100 \mathrm{~g})$ compared to Dongjin wild type $(1.37 \mu \mathrm{g} / 100 \mathrm{~g})$. Hence, a major proportion of polyglutamylated folates in grain would be dependent on the expression of FPGS Os03g02030 gene. Since embryo development occurs within a few days after anthesis stage (Counce et al. 2000), impaired folate polyglutamylation is likely to impact the rate of DNA synthesis, causing a delay in embryo development. Alternatively, the delayed grain phenotype exhibited by fpgs03g may reflect the impact on other folate-dependent processes such as the glycine-serine interconversion and methionine biosynthesis and biogenesis (Somerville, 2001, Wingler et al. 1997, Heineke et al. 2001, Moffatt and Weretilnyk, 2001, Gallardo et al. 2002).

The degree of glutamylation varies between developmental organs (Lowe et al. 1993). Tetra- and pentaglutamylated folate forms account mainly in pea leaves (Imeson et al. 1990) which is in agreement with rice folate profiles reported in this paper. 5-Formylpentaglutamate is a major polyglutamylated folate form in both rice leaf and grain. Changes in polyglutamylated folates level in rice organs are influenced by FPGS activity.
Considering on FPGS expression based on the transcript abundance, FPGS Os $10 g 35940$ increased approximately twofold in the knockout leaf suggesting the compensation of FPGS activity from FPGS Os $10 \mathrm{~g} 35940$ during the vegetative stage with no changing of the leaf phenotype. This compensation reflects no significant change of 5methyltetraglutamate and 5-methylpentaglutamate. However, approximately $39 \%$ decreasing of 5 -formylpentaglutamate in the knockout leaf suggests that the compensation of glutamylation of FPGS Os $10 \mathrm{~g} 35940$ in leaf might not be responsible to generating 5-formylpentaglutamate folate form.

In contrast, during grain development, FPGS Os $10 g 35940$ seems not to be affected and not show the compensation of FPGS activity as in the knockout grain, the levels of all polyglutamylated folate forms decreased significantly. Decreasing of 5-methyltetraglutamate and 5-methylpentaglutamate folate forms showed approximately $66 \%$ compared to wild type, whilst 5 -formylpentaglutamate decreased approximately $70 \%$. These results strongly suggest that FPGS Os03g02030 play a key role in glutamylation during grain development.

Interestingly, this study has shown that germination, the developmental stage reported to generate the greatest demand for folates (Jabrin et al. 2003, Gambonnet et al. 2001), was not affected in the fpgs $03 \mathrm{~g}$ mutant. This suggests that the remaining rice FPGS gene Os10g35940 can compensate for the lack of Os03g02030 activity during germination. Alternatively, this modification to folate polyglutamylation activity may not be essential during germination and embryo development such that enzymes normally dependent on polyglutamated folates are able to substitute them with monoglutamated folate forms. This idea could be supported by elevating of the transcript levels of GTPCHI, ADC synthase and HPPK/DHPS, monoglutamate folate synthesis genes, indicating the increasing of monoglutamate folate production. However, these possibilities will require the 
a

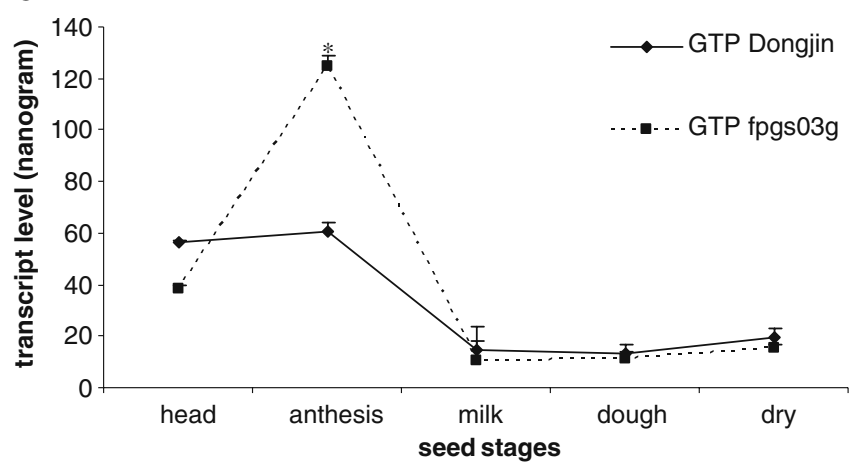

b

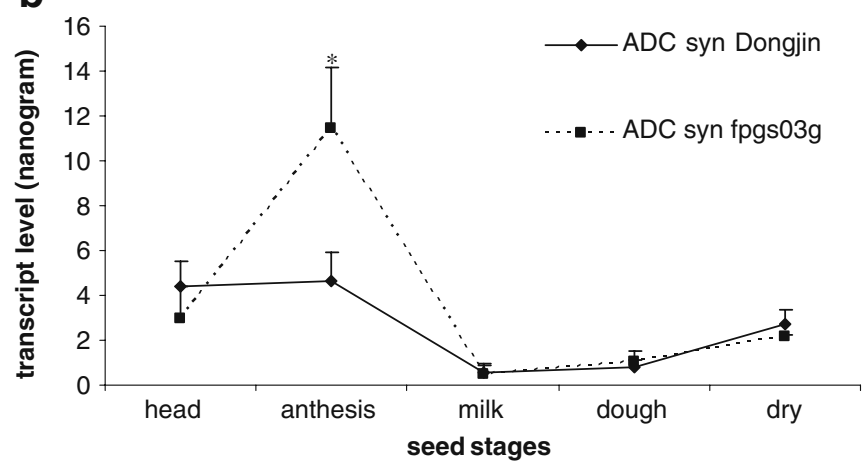

C

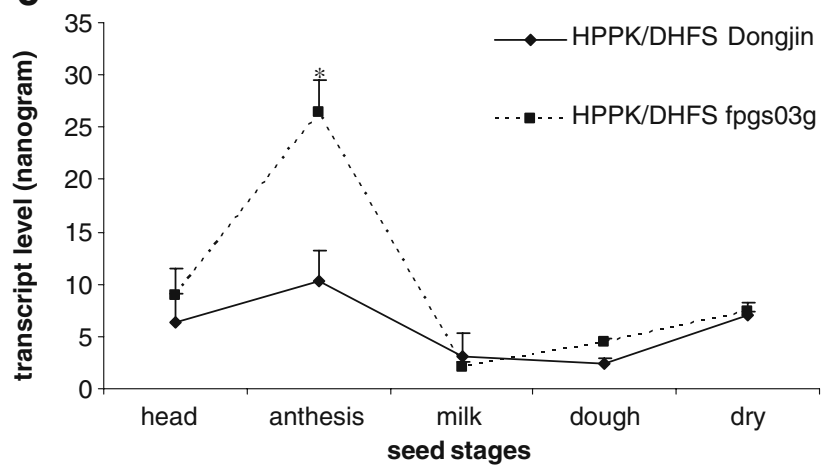

Fig. 8 Transcript profiling of folate-related genes during seed developmental stages was analysed by RT-qPCR in Dongjin wild-type and fpgs $03 \mathrm{~g}$ mutant. Per one determination, 40 fresh seeds from each stage from different five plants were pooled. Only dominant folaterelated genes was considered which are a GTPCHI LOC_Os04g56710 (GTP), b ADC synthase LOC Os06g48620 (ADC syn), c HPPK/DHPS LOC_Os07g42632 (HPPK/DHPS), d FPGS LOC_Os10g35940

characterisation of the phenotype of plants lacking both rice FPGS genes.

Folate biosynthesis gene expression is subject to feedback regulation

Molecular profiling of the fpgs03g knockout line has generated several new insights into the regulation of folate homeostasis in plants. Firstly, LC-MS/MS metabolite profiling of fpgs $03 \mathrm{~g}$ seed revealed a reduction in both mono- and polyglutamylated folate forms (Table 2). This result is in
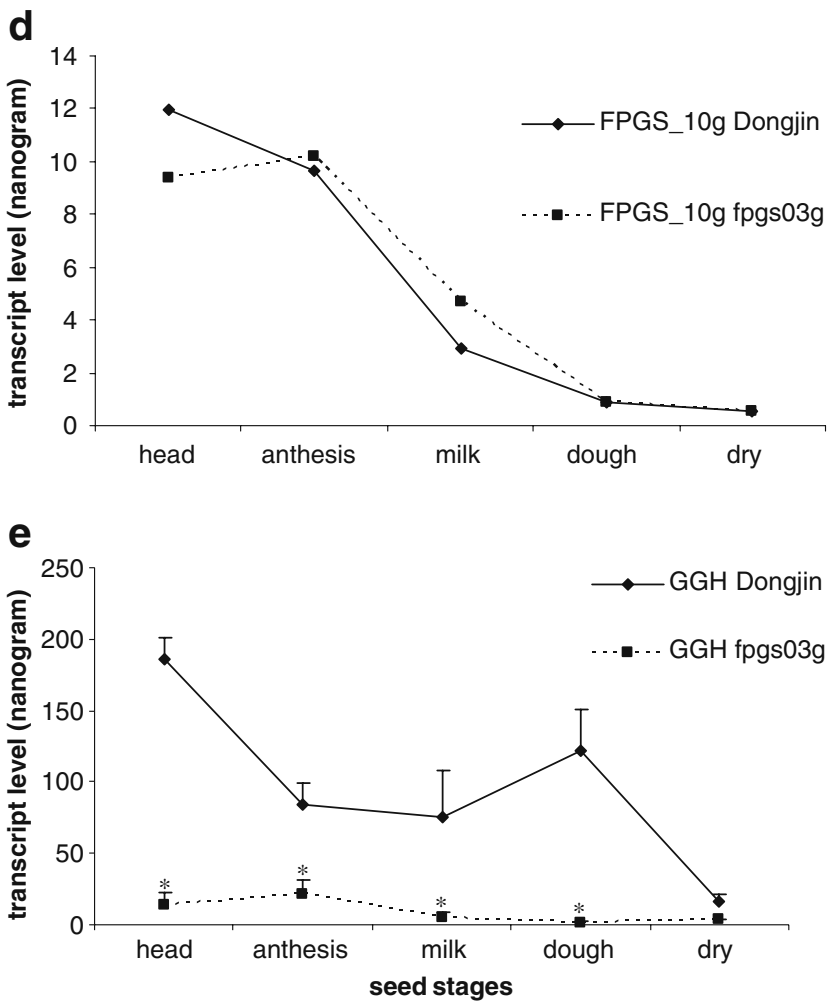

(FPGS_10g) and e GGH LOC_Os05g44130 (GGH). Head is heading stage of panicles. Anthesis is the flowering stage which is the first day of the florets open. Milk is the white milky liquid seed stage. Dough is the green hard dough seed stage. Dry is the brown mature seed stage. Each stage was profiled in triplicate. Asterisks represent the significant difference $(P<0.05)$ of transcript abundance compared between knockout and Dongjin wild type within tissues.

agreement with previous studies from a number of organisms which show that folate polyglutamylation is involved in retention and homeostasis of folates (Desouza et al. 2000; Lin et al. 1993; Lin and Shane, 1994). The reduction in monoglutamated folates may be a result of folate breakdown, as polyglutamylated protein-bound folates are less susceptible to oxidative breakdown (Suh et al. 2001).

All ten steps involved in the plant folate biosynthesis pathway have been described and characterised, and the expression of several enzymes involved in this pathway has been correlated with the folate pool and the carbon-one unit 
demands in various physiological situations (Basset et al., 2002, 2004a, 2004b; Jabrin et al., 2003). Indeed, this study has confirmed these previous observations, in that the reduction in folate abundance in tissues of the fpgs $03 \mathrm{~g}$ knockout line was shown to be correlated with an increased expression of a number of folate biosynthesis genes, namely GTPCHI, ADC synthase, ADC lyase and HPPK/DHPS compared to wild type (Fig. 7). Mutant plant appears to compensate for reduced polyglutamylation by increasing its substrate, monoglutamate folate, through increasing mRNA level of folate synthesis genes to maintain the folate pool. Interestingly, an increase in the expression of the second rice FPGS isoform (Os10g35940) in leaf (Fig. 8b) is coupled with a reduction in $G G H$ transcript levels in the fpgs03g knockout plant. This finding may indicate a mechanism by which the disrupted FPGS isoform is compensated by the functional rice FPGS, whilst the vacuolar folate deglutamylation is reduced and thus the cellular mono- and polyglutamate folate pools are maintained. The induced changes in transcript levels of folate biosynthetic genes as a result of folate depletion are an established mechanism in human cells, associated with intracellular folate retention (Hayashi et al. 2007). Future studies will focus on determining the molecular basis of this regulatory mechanism which will aid manipulation of folate abundance in plants.

\section{Methods}

\section{Plant materials}

Dry mature grains of rice (O. sativa) cultivar Dongjin and T-DNA knockout plants for FPGS Os03g02030 gene were obtained from Postech, Korea.

Rice growth condition

A number of rice seeds were germinated. They were soaked with distilled water on a Petri dish and kept in growth chamber at $26-28^{\circ} \mathrm{C}$ until germination. Germinated seeds were transfer into compost containing a 1:1 ratio of Levington M3 and John Innes no. 3. Pots were then placed in the same growth chamber at University of Nottingham, Sutton Bonington campus, UK with a 12-h light cycle at $28-30^{\circ} \mathrm{C}$ during the day and $21^{\circ} \mathrm{C}$ during the night.

\section{DNA isolation}

For genotyping of T-DNA knockout lines, their DNA was extracted from at least $100 \mathrm{mg}$ of leaves using MATAB (Sigma, UK). Rice mutant leaves were homogenised in liquid nitrogen. MATAB was pre-heated in $72^{\circ} \mathrm{C}$ water bath and added $900 \mu \mathrm{l}$ into homogenised samples. The reaction was incubated for $1 \mathrm{~h}$ with shaking every $15 \mathrm{~min}$. Then, $900 \mu 1$ of CIAA was added in each tube and centrifuged at $6,500 \mathrm{rpm}$ for $10 \mathrm{~min}$. The supernatant was removed into the new tube with 2 units of RNase (Novagen, Germany). The reaction was incubated at $37^{\circ} \mathrm{C}$ for $30 \mathrm{~min}$ and $900 \mu \mathrm{l}$ of CIAA was added into each tube before re-centrifugation at the same speed. The supernatant was transferred after centrifugation into a new tube, $720 \mu 1$ of isopropanol was added and kept at $4{ }^{\circ} \mathrm{C}$ for $10 \mathrm{~min}$. All the tubes were centrifuged, and the DNA pellet was collected. The pellet was washed with $1 \mathrm{ml}$ of $75 \%$ ethanol, dried, re-suspended in $50 \mu \mathrm{l}$ of sterile water and stored at $-20^{\circ} \mathrm{C}$.

\section{Southern blot analysis}

Genomic DNA $(5 \mu \mathrm{g})$ from T-DNA plants was digested with EcoRI enzyme and run on $0.8 \%$ agarose gel electrophoresis with a molecular DNA marker. DNA was transferred onto nylon membrane, then probed with $H P T$ gene and FPGS gene fragments (for primer sequences used to generate probe, see the Electronic Supplementary Material Table S2) labelled with alpha32P-dCTP. The membranes were generally washed once for $15 \mathrm{~min}$ in $0.5 \times \mathrm{SSC} / 0.1 \% \mathrm{SDS}$, once for $30 \mathrm{~min}$ in $0.5 \times \mathrm{SSC} / 0.1 \% \mathrm{SDS}$ and once for $15 \mathrm{~min}$ in $0.1 \times \mathrm{SSC} / 0.1 \% \mathrm{SDS}$. The washed membrane was subsequently exposed to the photosensitive card (Amersham cassettes) for 3 days at room temperature. A photo imager storm 820 Amersham scanner was used to visualise the genotype. The highest resolution of $50 \mu \mathrm{m}$ was used, and each image was scanned.

\section{Polymerase chain reaction}

To genotype FPGS Os03g02030 mutant lines, their genomic DNAs were amplified to detect the presence of the T-DNA insertion. The primers used for screening the wild-type plants were named 3gE1_for and 3gE4_rev. 3gE1_for and RB_rev primers were used for detecting the T-DNA insertion (for primer sequences, see the Electronic Supplementary Material Table S3). For testing gene expression by RT-PCR, primers 3gE1_for and 3gE11_rev were used. The expected fragments from each primer pair were amplified from $10 \mathrm{ng}$ of rice DNA using $10 \mathrm{pmol}$ of gene specific primers in $25 \mu \mathrm{l}$ of the reaction mixture containing $10 \times$ PCR buffer, $1.5 \mathrm{mM} \mathrm{MgCl} 2,0.2 \mathrm{mM}$ dNTPs (Promega, UK) and 1 unit of Taq DNA polymerase (red hot Taq polymerase, ABgene, UK). The PCR conditions used to amplify the genes of interest were as follows: an initial denaturation step of 2 min at $94^{\circ} \mathrm{C}, 35$ cycles of $30 \mathrm{~s}$ for denaturation at $94^{\circ} \mathrm{C}, 30 \mathrm{~s}$ for annealing at $(\mathrm{Ta})^{\circ} \mathrm{C}$ (depends on primer pairs, see the Electronic Supplementary Material Table S3) and $1 \mathrm{~min}$ for the extension step at $72^{\circ} \mathrm{C}$. The final extension was carried 
out for one cycle at $72^{\circ} \mathrm{C}, 10 \mathrm{~min}$. The PCR products were analysed on a $1 \%$ agarose gel containing $0.4 \mu \mathrm{g} / \mathrm{ml}$ ethidium bromide. Gels were visualised using a Gel Doc EV500 scanner (Syngene, UK).

\section{Sample preparation for all RT-qPCR assay}

The third green leaf of 2-week-old wild-type and mutant plants was collected in $1.5 \mathrm{ml}$ eppendorf tube from at least five plants per pool. At least three pools of samples were collected. All leaf samples were homogenised in liquid nitrogen using pestles and kept at $-80^{\circ} \mathrm{C}$ until RNA isolation. To prepare grain samples for RT-qPCR analysis, the outer layer of approximately 40 dry seeds was removed by hand. All brown seeds were ground together with Retsch ${ }^{\circledR}$ MM301 ball mill equipment at frequency of 30 $1 \mathrm{~s}^{-1}$ for $1 \mathrm{~min}$. Ground samples were stored at $-80^{\circ} \mathrm{C}$ until RNA isolation.

\section{RNA isolation}

Total RNA was extracted from collected rice samples by using TRIzol reagent (Invitrogen, UK) according to the manufacturer's protocol. In brief, plant samples were homogenised in liquid nitrogen, $1 \mathrm{ml}$ of TRIzol reagent was added to $100 \mathrm{mg}$ of homogenised samples and was mixed thoroughly. After centrifugation at $11,400 \mathrm{rpm}$ for $10 \mathrm{~min}$ at $4^{\circ} \mathrm{C}$ to remove cell debris, $200 \mu \mathrm{l}$ of chloroform was added and mixed by vigorous shaking for $15 \mathrm{~s}$. After centrifugation at the same speed, the aqueous phase was kept. To precipitate RNA, $500 \mu 1$ of isopropanol was added. For glycogen-rich samples such as grains, $250 \mu \mathrm{l}$ of isopropanol and $250 \mu \mathrm{l}$ of $0.8 \mathrm{M}$ sodium citrate containing 1.2 $\mathrm{M}$ sodium chloride solution were added instead. After 10 min incubation at room temperature, the mixture was centrifuged at the same speed mentioned above and RNA pellet was kept. The pellet was washed by $75 \%$ ethanol, resuspended in $180 \mu \mathrm{l}$ of distilled water and treated with DNase enzyme (RNase-free DNase, Promega, UK) at $37^{\circ} \mathrm{C}$ for $30 \mathrm{~min}$. RNA was cleaned up using phenol/chloroform. Treated total RNA was stored at $-80^{\circ} \mathrm{C}$.

\section{cDNA synthesis}

First-stranded cDNAs were synthesised from $500 \mathrm{ng}$ of treated total RNA with Superscipt ${ }^{\mathrm{TM}}$ II reverse transcriptase (Invitrogen, UK) follow the manufacturer's protocol. Briefly, 100 pmole of oligo(dT) primer and $10 \mathrm{mM}$ dNTPs were added into $500 \mathrm{ng}$ of total RNA in $13 \mu \mathrm{l}$ total reaction. After heating at $65^{\circ} \mathrm{C}$ for $5 \mathrm{~min}, 4 \mu \mathrm{l}$ of $5 \times$ first-strand buffer, $2 \mu 1$ of $0.1 \mathrm{M}$ DTT were added and incubated the reaction initially at $42^{\circ} \mathrm{C}$ for $2 \mathrm{~min}$. Then, $1 \mu \mathrm{l}$ of reverse transcriptase enzyme were added and extended incubation at $42^{\circ} \mathrm{C}$ for $2 \mathrm{~h}$. This reaction was then inactivated by heating at $70^{\circ} \mathrm{C}$ for $15 \mathrm{~min}$.

Quantitative real-time PCR

The absolute qPCR assays were performed on Corbett Rotorgene 6000 QPCR system (Corbett life science, UK) using SYBR Green I detection kit (Stratagene, UK). The PCR condition for short targets $(<300 \mathrm{bp})$ were as follows: one cycle of $10 \mathrm{~min}$ initial denaturation step at $95^{\circ} \mathrm{C}, 40$ cycles of $30 \mathrm{~s}$ denaturation step at $95^{\circ} \mathrm{C}, 1 \mathrm{~min}$ annealing step at $55^{\circ} \mathrm{C}$ or $58^{\circ} \mathrm{C}$ (depends on probes, see the Electronic Supplementary Material Table S4) and 1 min extension step at $72^{\circ} \mathrm{C}$. The melting curve was run from $55^{\circ} \mathrm{C}$ or $58^{\circ} \mathrm{C}$ to $90^{\circ} \mathrm{C}$ for checking a single band of a specific product. A standard curve was prepared with known DNA concentration of $60 \mathrm{ng} / \mu \mathrm{l}, 15 \mathrm{ng} / \mu \mathrm{l}, 1.5 \mathrm{ng} / \mu \mathrm{l}, 150 \mathrm{pg} / \mu \mathrm{l}$ and $15 \mathrm{pg} / \mu \mathrm{l}$. The gene expression levels were interpreted by comparing the threshold cycles of samples to the linear standard curve. The acceptable standard curve should reach 90$110 \%$ reaction efficiency and 0.975 or greater of an amplification efficiency value based on the instruction manual of the machine. The absolute expression value of each folate-related gene was normalised to the expression level of the rice actin gene. At least three replicates were performed per sample. The expression values of each gene were statistically compared using SPSS version 14.0. A probability value of less than $5 \%$ was considered statistically significant.

Folates extraction from rice leaf and grain samples

Three replicates of rice grain $(0.5 \mathrm{~g})$ and of leaf samples $(0.2 \mathrm{~g})$ were homogenised using Retsch ${ }^{\circledR}$ MM301 ball mill equipment and mixed with $1 \mathrm{ml}$ ice-cold $95 \%$ methanol/ phosphate extraction buffer $(75 \mathrm{mM} \mathrm{KH} 2 \mathrm{PO} 4,0.4 \mathrm{M}$ ascorbic acid, 0.8\% 2-mercaptoethanol, pH6.0) and $25 \mu \mathrm{l}$ internal standard mixture consisting of $0.1 \mathrm{mg} / \mathrm{ml}$ of each of methotrexate, triglutamic acid and hexaglutamic acid (1:1:1 $v / v)$ for $15 \mathrm{~min}$. The sample extracts were centrifuged $\left(15,000 \mathrm{~g}, 10 \mathrm{~min}, 4^{\circ} \mathrm{C}\right)$, and the supernatants were filtered through a $0.45 \mu \mathrm{m}$ Whatman Vectaspin microfilter $\left(15,000 \mathrm{~g}, 3 \mathrm{~min}, 4^{\circ} \mathrm{C}\right)$. They were evaporated to dryness under nitrogen gas and re-suspended in $200 \mu \mathrm{l}$ of extraction buffer $(75 \mathrm{mM} \mathrm{KH} 2 \mathrm{PO} 4,52 \mathrm{mM}$ ascorbic acid, $0.1 \% 2$ mercaptoethanol, $\mathrm{pH} 6.0$ ). Samples were kept at $-80^{\circ} \mathrm{C}$ until used or maintained at $4^{\circ} \mathrm{C}$ in the HPLC autosampler before LC-MS/MS analysis.

\section{LC-MS/MS measurement of folates}

The LC-MS/MS method was based on a previously described method (Garratt et al., 2005). HPLC analysis 
was performed using Shimadzu VP series HPLC system (Milton Keynes, UK) using a Luna C18 (2) $100 \AA$ analytical column $(150 \times 2.00 \mathrm{~mm}$, 5.im particle size $)$ and a compatible C1 8 guard column (Phenomenex,Macclesfield, UK). Mobile phase A consisted of methanol/water $(5: 95, v / v)$ with $5 \mathrm{mM}$ dimethylhexylamine, $\mathrm{pH} 8.1$ and mobile phase $\mathrm{B}$ was $5 \mathrm{mM}$ dimethylhexylamine in methanol. A linear gradient from $22 \%$ B to $80 \%$ B over 20.5 min was followed by a 5 -min isocratic hold at $80 \% \mathrm{~B}$ and re-equilibration for $12.5 \mathrm{~min}$ at $22 \% \mathrm{~B}$. The flow rate was $200 . \mathrm{iL} / \mathrm{min}$, and the injection volume was 20 .iL. The column was maintained at $35^{\circ} \mathrm{C}$ throughout the run.

A hybrid triple quadrupole ion trap mass spectrometer (4000 QTRAP) from Applied Biosystems (Foster City, CA, USA) was run using negative polarity. The TurboIonSpray source conditions were optimised for optimal ionisation of folates as follows: gas 1 and 2 at 20 and curtain gas at 40 . The ion spray voltage was set at $4 \mathrm{kV}$, and the turbo probe was heated at $500^{\circ} \mathrm{C}$. Declustering potential and collision energies for each folate standard were optimised for compound-dependent parameters using the quantitative optimisation wizard of the Analyst software (version 1.4.2).

Quantification of individual folate used three internal standards and extracted calibration standards for all the folate species and confirmation of folate structural identity was confirmed by comparison with an in-house folate spectral library. Significance of differences for the means of folate analytes, total folate concentration and percent distribution of folate derivatives in different samples and treatments were analysed by one way ANOVA using Tukey method.

Acknowledgment $\mathrm{PhD}$ funding was supported by the Royal Thai Government for Nampeung Anukul and by the Ford Foundation International Fellowships Program, Institute of International Education for Riza Abilgos Ramos. We thank Dr. Chungui Lu and Nottingham Trent University for access to the real-time PCR machine and for practical suggestions. Part of the work was carried on the RicE FUnctional GEnomics international hosting platform (Montpellier, France) funded by Agropolis Foundation.

\section{References}

Basset GJ, Quinlivan EP, Ziemak MJ, Díaz de la Garza R, Fischer M, Schiffmann S, et al. Folate synthesis in plants: the first step of the pterin branch is mediated by a unique bimodular GTP cyclohydrolase I. Proc Natl Acad Sci USA. 2002;99:12489-94.

Basset GJ, Quinlivan EP, Ravanel S, Rébeillé F, Nichols BP, Shinozaki K, et al. Folate synthesis in plants: the paminobenzoate branch is initiated by a bifunctional PabA-PabB protein that is targeted to plastids. Proc Natl Acad Sci USA. 2004a; 101:1496-501.

Basset GJ, Ravanel S, Quinlivan EP, White R, Giovannoni JJ, Rébeillé $\mathrm{F}$, et al. Folate synthesis in plants: the last step of the paminobenzoate branch is catalyzed by a plastidial aminodeoxychorismate lyase. Plant J. 2004b;40:453-61.
Bauwe H, Kolukisaoglu U. Genetic manipulation of glycine decarboxylation. J Exp Bot. 2003;54:1523-35.

Besson V, Rebeille F, Neuburger M, Douce R, Cossin EA. Effects of tetrahydrofolate polyglutamates on the kinetic parameters of serine hydroxymethyltransferase and glycine decarboxylase from pea leaf mitochondria. Biochem J. 1993;292:425-30.

Chen L, Qi H, Korenberg J, Garrow TA, Choi Y-J, Shane B. Purification and properties of human cytosolic folylpoly-gamma-glutamate synthetase and organization, localization, and differential splicing of its gene. J Biol Chem. 1996;271:13077-87.

Cossins E, Chen L. Folates and one-carbon metabolism in plants and fungi. Phytochemistry. 1997;45:437-52.

Counce PA, Keisling TC, Mitchell AJ. A uniform, objective and adaptive system for expressing rice development. Crop Sci. 2000;40:436-43.

DeSouza L, Shen Y, Bognar A. Disruption of cytoplasmic and mitochondrial folylpolyglutamate synthetase activity in Saccharomyces cerevisiae. Arch Biochem Biophys. 2000;376:299312.

Díaz de la Garza R, Quinlivan EP, Klaus SMJ, Basset GJC, Gregory III JF, Hanson AD. Folate biofortification in tomatoes by engineering the pteridine branch of folate synthesis. Proc Natl Acad Sci USA. 2004;101:13720-5.

Galivan O, Ryan TJ, Chave K, Rhee M, Yao R, Yin D. Glutamyl hydrolase: pharmacological role and enzymatic characterization. Pharmacol Ther. 2000;85(207-21):5.

Gallardo K, Job C, Groot SPC, Puype M, Demol H, Vandekerckhove $\mathrm{J}$, et al. Proteomics of Arabidopsis seed germination. A comparative study of wild-type and gibberellin-deficient seeds. Plant Physiol. 2002;129:823-37.

Gambonnet B, Jabrin S, Ravanel S, Karan M, Douce R, Rebeille F. Folate distribution during higher plant development. J Sci Food Agric. 2001;81:835-41.

Garratt LC, Ortori CA, Tucker GA, Sablitzky F, Bennett MJ, Barrett DA. Comprehensive metabolic profiling of mono- and polyglutamylated folates and their precursors in plant and animal tissue using liquid chromatography-negative ion electrospray ionisation tandem mass spectrometry. Rapid Commun Mass Spectrom. 2005; 19:2390-8.

Hanson AD, Roje S. One-carbon metabolism in higher plants. Annu Rev Plant Physiol Plant Mol Biol. 2001;52:119-37.

Hanson AD, Gregory JFIII. Synthesis and turnover of folates in plants. Curr Opin Plant Biol. 2002;5:244-9.

Hayashi I, Sohn K, Stempak J, Croxford R, Kim Y. Folate deficiency induces cell-specific changes in the steady-state transcript levels of genes involved in folate metabolism and 1-carbon transfer reactions in human colonic epithelial cells. J Nutr. 2007;137 (607-61):3.

Heineke D, Bykova N, Gardestrom P, Bauwe H. Metabolic response of potato plants to an antisense reduction of the p-protein of glycine decarboxylase. Planta. 2001;212:880-7.

Imeson $\mathrm{H}$, Zheng L, Cossins EA. Folylpolyglutamate derivatives of Pisum sativum L. Determination of polyglutamate chain lengths by high performance liquid chromatography following conversion to p-aminobenzoylpolyglutamates. Plant Cell Physiol. 1990;31:223-31.

Jabrin S, Ravanel S, Gambonnet B, Douce R, Rébeillé F. One-carbon metabolism in plants. Regulation of tetrahydrofolate synthesis during germination and seedling development. Plant Physiol. 2003;131:1431-9.

Jones ML, Nixon PF. Tetrahydrofolates are greatly stabilized by binding to bovine milk folate-binding protein. J Nutr. 2002;132:2690-4.

Lin BF, Shane B. Expression of Escherichia coli folylpolyglutamate synthetase in the Chinese hamster ovary cell mitochondrion. J Biol Chem. 1994;269(9705-971):3. 
Lin BF, Huang RS, Shane B. Regulation of folate and one-carbon metabolism in mammalian cells III. Role of mitochondrial folylpoly- $\gamma$-glutamate synthetase. J Biol Chem. 1993;268:21 674-9.

Lowe KR, Osborne CB, Lin BF, Kim JS, Hsu JC, Shane B. Regulation of folate and one-carbon metabolism in mammalian cells II. Effect of folypoly- $\gamma$-glutamate synthetase substrate specificity and level on folate metabolism and folypoly- $\gamma-$ glutamate specificity of metabolic cycles of one-carbon metabolism. J Biol Chem. 1993;268:21 665-73.

Moffatt BA, Weretilnyk EA. Sustaining S-adenosyl-1-methioninedependent methyltransferase activity in plant cells. Physiol Plant. 2001;113:435-42.

Orsomando G, Diaz de la Garza RD, Green BJ, Peng M, Rea PA, Ryan TJ, et al. Plant gamma-glutamyl hydrolases and folate polyglutamates: characterization, compartmentation, and cooccurrence in vacuoles. J Biol Chem. 2005;280:28877.

Ravanel S, Cherest H, Jabrin S, Grunwald D, Surdin-Kerjan Y, Douce $\mathrm{R}$, et al. Tetrahydrofolate biosynthesis in plants: molecular and functional characterization of dihydrofolate synthetase and three isoforms of folylpolyglutamate synthetase in Arabidopsis thaliana. Proc Natl Acad Sci USA. 2001;98:15360-5.
Ravanel S, Block MA, Rippert P, Jabrin S, Curien G, Rebeille F, et al. Methionine metabolism in plants: chloroplasts are autonomous for de novo methionine synthesis and can import S-adenosylmethionine from the cytosol. J Biol Chem. 2004;279:22548-57.

Shane B. Folylpolyglutamate synthesis and role in the regulation of one-carbon metabolism. Vitam Horm. 1989;45:263-335.

Somerville CR. An early Arabidopsis demonstration resolving a few issues concerning photorespiration. Plant Physiol. 2001;125:20-4.

Suh JR, Herbig AK, Stover P. New perspectives on folate catabolism. Annu Rev Nutr. 2001;21:255-82.

Sun X, Cross JA, Bognar AL, Baker EN, Smith CA. Folate-binding triggers the activation of folylpolyglutamate synthetase. J Mol Biol. 2001;310:1067-78.

Storozhenko S, Brouwer VD, Volckaert M, Navarrete O, Blancquaert D, Zhang GF, et al. Folate fortification of rice by metabolic engineering. Nat Biotechnol. 2007;25(1277-1):279.

Wang Y, Nimec Z, Ryan TJ, Dias JA, Galivan J. The properties of the secreted gamma-glutamyl hydrolases from H35 hepatoma cells. Biochim Biophys Acta. 1993;1164:227-35.

Wingler A, Lea PJ, Leegood RC. Control of photosynthesis in barley plants with reduced activities of glycine decarboxylase. Planta. 1997;202:171-8. 